\title{
Hierarchy, strategic assets and distinctive capabilities in Scottish organised crime
}

\author{
Kenneth Murray ${ }^{1}$
}

\section{Introduction}

This chapter considers the significance of hierarchy in Scottish organised crime: the evidence that supports its existence and the conditions that are necessary for its occurrence. In doing so the chapter examines how Serious Organised Crime Groups ('SOCGs') in Scotland compete in their principal markets, both criminal and legitimate, focussing on the market factors and dynamics that are necessary for survival, endurance and dominance. On this basis, a platform for analysis is proposed which is designed to assist in identifying the distinctive capabilities of dominant SOCGs and how these have enabled the development of the strategic assets form the basis of their hierarchical strength. A practical application of this approach is proposed to enable SOCG vulnerabilities to be identified such that their activities and influence, not least in legitimate markets, can be curtailed, or at least more effectively constrained.

\section{Tackling organised crime in Scotland}

The official approach to tackling serious organised crime in Scotland is set by a Scottish Government body known as the 'Serious Organised Crime Task Force' ('SOCTF'). SOCTF uses a thematic strategy known as the 4 'D's (Detect, Disrupt, Divert and Deter), which emphasises awareness raising and partnership working, as well as traditional law enforcement

\footnotetext{
1 The author is Head of Forensic Accountancy at Police Scotland. The views expressed here are his own and should not be read as being those of Police Scotland.
} 
measures, in an effort to demonstrate that Scotland is a hostile environment for organised crime. Within law enforcement, the principal operational decisions about how resources should be deployed in this context are set by a mapping process, known as Serious Organised Crime Mapping ('SOCM'). This process collates all available relevant intelligence relating to serious organised crime ('SOC') and ranks SOCGs in accordance with how they score on a harm matrix. This scoring process explicitly identifies and defines these groups according to structures of hierarchy: SOCGs are essentially discerned by means of tracked hierarchical relationships between individual SOCG players (known as 'nominals') within them.

The SOCM process provided much of the source material for a recent Scottish Government study entitled 'Serious Organised Crime in Scotland: A Summary of the Evidence' (Scottish Government, 2017). In considering what it referred to as 'the evidence' about serious organised crime in Scotland, this document augmented interpretations of mapping data with a review of academic literature. It drew the conclusion that "in order to disrupt and weaken SOC activity, a fuller understanding of the structure, operation and behaviour of SOC groups is required." On this foundation the report assessed:

“... it is important to recognise that while SOC groups are often very hierarchical and highly structured, SOC groups come in a variety of shapes and forms, which also includes very loose networks of criminal actors ... Recognising the diverse structures and compositions of SOC groups is critical to understanding how SOC can be tackled." (pp. 1617).

It is one thing to observe that a garden is full of many different flowers (or maybe we should say weeds) but another to explain how they actually grow. What do they need to grow? Why do some, if they are allowed to, appear to take over the whole allotment? The 'social construct' conception of organised crime, whereby all the various kinds of collective criminality that might attract the 'OC' label are collected under an 'umbrella' (Von Lampe, 2016 a and b), provides a suitable basis for describing the many facets of organised crime, but its value as a guide to SOC dynamics is limited. Recognising diversity of SOC type in itself does little to assist in de- 
vising strategies of tackling its harms. What is required is a way of understanding SOCGs primarily in terms of what they do rather than how they can be described or classified.

\section{Hierarchy versus network - a false dichotomy}

Re-focussing on what SOCGs do serves some way to providing clarity on the vexed question of whether SOC can be best conceived in terms of a market/hierarchy framework or a network structure (Campana, 2016b). In simple terms: SOCGs are formed because some crimes requiring a measure of organising to carry them out. One-off crimes may only require temporary arrangements which can dissolve when the crime is complete. Where there is a profit to be made from repeat activity, then a mode of association that might be described as organisation starts to form. It might of course be argued that there are other formational influences on organised crime groups than the market, but the Finckenauer assertion that "making a profit is in fact the primary goal of organised crime groups" (Finckenauer, 2005: 66 ) is a difficult one to refute. This is not the same as saying all organised crime groups have been formed in response to market opportunities. But it does imply that, whatever their provenance, they have to adapt to the markets they participate in to survive, or otherwise they fail. The market imposes an organisational conduct. The question is how do SOC players engaged in criminal markets associate in order to accommodate the conditions that they face?

There is a tradition in the academic literature which posits a contrast between SOC conceived in terms of 'mafias' or hierarches, and conceptions based on networks. Morselli described a 'debate' between law enforcement treatments of SOC and network based treatments favoured by academics.

"The debate in brief is whether the organisation of the distribution of illegal drugs is more likely an orthodox pyramid-based governance structure regulated by strong-hand criminal dictators, or the 'armslength' transactional process (Naylor, 1997) that so resembles dealings in legitimate cross border business" (Morselli, 1999: 27). This point of view was given further amplification by Dick Hobbs: "the notion of crime groups as tightly organised hierarchical entities whose tentacles 
reach around the globe is not supported by the evidence, and this market should be understood as one that is populated by networks or partnerships of independent traders or brokers." (Hobbs, 2013: 156)

In Hobbs' view, associating 'mafia's' with territorial domination is no longer valid, SOC markets are more accurately characterised as "different kinds of brokerage and ever-mutating, interlocking networks featuring a variety of links with similar entities in other neighbourhoods." (Hobbs, 2013: 218).

So, why does hierarchy continue to have relevance in Scottish SOC? The Scottish Government report clearly accepts that structured hierarchical SOCGs still exist, something that will be evidenced in more detail below. The Scottish SOC theatre, especially in the Central Belt, continues to demonstrate the existence of dominant territorial influences, although it is fair to say from current practitioner experience the foundations for dominance may be moving away from territory to ability to access supply routes and specialist services. The SOCM process on the other hand is based on understanding the associative links that connect SOC in Scotland across a network. The SOC challenge in Scotland therefore involves modes of association within illegal markets that are both hierarchical and which involve networks. This would appear to chime with Campana's assertion that in order to capture the reality of SOC, an instrumental approach to networks is needed which is able to elucidate the continuum that exists between market conduct and hierarchic operating in its various forms (Campana, 2016b). Any meaningful analysis of Scottish SOC therefore has to accommodate both types of association. There is a continuing need to articulate how hierarchical influence continues to arises and flourish in SOC and how this influence interacts with, and is expressed through, network forms of association.

\section{Transactional dynamics in understanding SOC}

What are the key factors or characteristics that account for economic success in organised crime? Answering this satisfactorily requires an understanding of the dynamic forces that form, nurture, create and destroy SOCGs. Categorisations in accordance with type, shape, form, or other defining factors such as ethnicity, inform in terms of describing groups of 
participants engaged in SOC, but descriptions in themselves don't tell us enough about how or why SOCGs succeed or fail; what factors are at play in determining these outcomes, and also the many partial successes and failures that lie between them.

All SOCs transact. They all deal in criminal markets and most above a certain level deal in legitimate markets too. Analysis of the attributes and characteristics that enable SOCs to transact successfully in these markets can answer many of the questions that arise in relation to them: for example those relating to identity, purpose, character, method, vulnerabilities and weaknesses. It follows that a better understanding of the constituent factors that make SOCs successful in transacting with others will in turn provide better understanding of the forces that influence the development of SOC structure. For example, in terms of understanding how hierarchical structures interact with network structures, and why hierarchical structures continue to be suited to market dynamics at the top end of markets and why networks are more suited to the bottom end, where they are the dominant form of association.

Illegal drug markets rely on longitudinal interfaces between hierarchical and network modes of structure which have to function together. High value importations and street corner retail are two ends of the same business process, and the part played by an SOCG in that process is determined by what they are able to contribute to it. In most cases this refers to what they are allowed to do in these markets in accordance with whatever hierarchical influences they are subject to. The influence of hierarchy in other words is not a concept that is best considered in opposition to network forms of association, but rather, in the context of SOC, an influence that is present and part of the networks, both relevant to all serious SOC markets. Because of this, the existence of hierarchical influence in these markets provides a door of analysis through which the networks they interact with can be understood too. 


\section{The Serious Organised Crime Mapping Process ('SOCM')}

It is on the basis of identifying hierarchical relationships that the SOCM process approaches its challenge of identifying and prioritising SOC threats and where they come from. Using intelligence data sweeps from all relevant intelligence sources throughout Scotland, this process categorises featured players in the relevant intelligence disseminations as principals, members, associates and rivals. The network analysis applied to the relevant intelligence considers the suitability of each nominal to these classifications (using a variety of sources, such as telephone billings and surveillance $\operatorname{logs}$ ). Using conventional network analysis tools, the process assesses connectedness of nominals, or nodes, and these are differentiated in terms of degree and between-ness centrality (essentially in the same way as Morselli discusses in his analysis of Canadian Hell's Angels) (Morselli, 2010). High degree centrality counts the number of connections, whereas between-ness centrality assesses the strategic importance of connections between otherwise disconnected others.

The base objective of this stage in the SOCM process is to establish what the hierarchical relationships are (as defined on this basis). These are then used to build an understanding of group structure. In this regard, the nominals identified as 'principals' and 'members' are of most importance. 'Associates' often demonstrate a high degree of centrality, but may flit from 'group' to 'group' or influence to influence. In strategic terms, however, these nominals may be important enablers, providing specialist services to a number of groups or centre of influence. The data sweep is then used to develop an understanding of the activities and capabilities of each group through the compilation of a harm matrix. This generates a threat score supported by a justification document. The organised crime groups are ranked in accordance with their threat score and this is fed into the tasking process, which determines how resources are to be deployed operationally. 
The latest available mapping report at the time of writing ${ }^{2}$ provides the following profile of organised crime groups and connections:

- 132 Serious Organised Crime Groups (SOCGs) were mapped;

- 89 of these SOCGs contained a total of 335 individuals who had connections to multiple groups; the most connected individuals (i.e. those individuals with links to more than 7 SOCGs) were all principals of their own group and each had links to at least 9 groups including their own;

- the 13 most connected nominals were linked to a total of 37 SOCGs;

- of 84 nominals identified as specialists, one quarter were identified as being connected to more than one group.

- $70 \%$ of SOCGs (104) were involved in 'quasi-legitimate' enterprises involving 674 identified companies.

SOCM provides an indicator of what harm SOCs threaten most as conveyed by historic intelligence. The quality of that intelligence is therefore crucial to the value of the SOCM output. Over the past five years, there has been a concerted effort within Police Scotland to broaden the base of the intelligence captured, and financial and business intelligence is now given an emphasis commensurate with the more traditional areas of law enforcement intelligence gathering.

SOCM relies on establishing group identity through identification of hierarchical relationships between individuals (known as 'nominals'). While this can enable hierarchical relationships between SOC groups to be discerned, it cannot on its own provide an analysis of the market and transactional dynamics that underpin hierarchical intra group relationships. SOCM in other words identifies which SOCGs are most active and possess most threat, but requires this further mode of analysis to determine why these SOCGs are prominent in the rankings. What are the factors that got them there and keep them there? The incorporation of transactional dynamics into the picture, therefore, requires a further mode of analysis in order to complete the picture when it comes to understanding hierarchy. That mode of analysis must be capable of providing a dynamic dimension

2 The source is the Scottish Organised Crime Group Mapping Report (SOGM) 2017/19 Q4 and Year End April 2018, which is a classified document and is not included in the list of references provided below 
to the periodic snapshot pictures provided by SOCM. Recent law enforcement successes in Operation Escalade provided an outstanding field opportunity to study the foundations of hierarchy in Scottish SOC.

\section{Operation Escalade}

In 2017, the Escalade SOCG was ranked number one not only in the Scottish mapping rankings, but also those relating to the UK as a whole. Of particular significance in the context of examining hierarchical influence, a number of other high-ranking Scottish SOCGs (i.e. within the top ten in the SOCM rankings) were also the Escalade SOCGs customers.

In December 2017, nine individuals connected with the Escalade SOCG were convicted for a variety of organised crime offences. Each of these individuals was identified by the SOCM as a 'serious organised crime' player. At the relevant High Court hearing, prosecuting counsel, Alex Prentice QC, described the relevant SOCG group as follows:

"The Organised Crime Group is the most sophisticated group encountered by Police Scotland. Their operation centres on the importation of vast quantities of cocaine. Their role is as wholesalers to other organised crime groups. They are the top of the chain in terms of drugs transactions in Scotland and the United Kingdom as a whole. The amount of cash and firearms recovered in this case was indicative of an international operation." (Daily Record, 2017b)

The picture painted by Mr Prentice for the court was designed to convey how serious the crimes were and how worthy the convicted individuals were of substantial sentences. The individuals convicted, however, were not the principals of that group, but essentially constituted its core operational management in Scotland. The lead principals of the SOCG were other nominals identified in SOCM, whose methods of delegation and displacement enabled them, up to that point (at the time of writing it is an ongoing operation), to protect themselves from direct evidential connection with the crimes for which the operatives who worked for them were convicted. In February 2019, these lead individuals were identified publicly as Barry and James Gillespie (Sunday Mail, 2019), and they remain at large at the time of writing. 
The size of the cash hauls involved from Operation Escalade disclosed at trial amounted to some $£ 1,6$ million, a signifier of the operational importance of the convicted individuals to the SOCG. In terms of the estimated profits earned by the SOCG, this amount was estimated to be roughly equivalent to the revenues it earned across the UK in one week. The circumstances leading to their arrest and conviction directly related to the debt enforcement methods they used when seeking payment for supply of imported cocaine. The press reports provided lurid detail of these methods, which included extended torture of a victim debtor including chain whippings, treating his open wounds with bleach, shooting him in both knee caps and rolling him down a hill close to his home. The drug debt owed by the victim concerned was only $£ 30.000$; in the course of his ordeal, however, he was advised by one of his tormentors that: "It wasn't the money, it was the principle". The need to be seen to exert discipline in respect of a relatively low debt indicated the importance accorded by the SOCG to its reputation, one which still persists. The ability to dispense violence by itself, however, does not explain how the Escalade SOCG managed to acquire such a degree of dominance. Most SOCGs in Scotland are well capable of violence. So the exceptional success and market dominance of the Escalade SOCG requires some further explanation.

As indicated, the business of the Escalade SOCG was the supply of high purity drugs to high level customers, for the most part other high ranking SOCGs. The Escalade SOCG was a primary importer of Class A drugs into Scotland, and also managed and controlled supply lines into London, Liverpool and Manchester. The key attribute that enabled the SOCG to attain this position was the direct supply contacts it had established with producer cartels in South America, enabling it to control the importation and transport of commodity across Europe and in the UK itself, and bypassing more established European channels of supply. The Escalade SOCG instead developed its own supply chain by creating an extensive network of logistics and physical storage assets across Western Europe, extending in particular into the Iberian Peninsula. Through a network of warehouses and transport vehicles it was able to co-ordinate transports of imported commodity from their landing points, mainly on the Iberian coast, to locations in the Netherlands. Stock piles of commodity were accumulated in Dutch warehouses to form a 'mother-load' from which wholesale shipments could be dispensed to the UK. In this way, the SOCG was able to control 
and maintain desired wholesale price levels on the British mainland. Once imported, the management of supply to major UK distributors was achieved through a network of warehouses and transactional relationships with high ranking Scottish SOCGs, each of whom were able to exert their own regional dominance in order to exert the necessary discipline and control of widely dispersed local distribution networks.

All distributors supplied with Escalade commodity were subject to detailed oversight and scrutiny through the monitoring of activity and financial accounts - an effort supported, where and when required, by enforcement techniques characterised by extreme violence, including murder, abduction, torture, firearms and the use of bladed weapons. In some cases, this has led to tensions developing with some of the other major SOCG nominals in Scotland, or the businesses they are/were associated with. (Daily Record, 2017b)

The character of the Escalade SOCG's transactional relations (as disclosed by SOCM), together with the hierarchical traits characteristic of many of their customers, underpin the assertion that hierarchy is still a prominent feature in Scottish SOC. Given the apparently dominant influence these SOCGs have in Scotland, particularly in the area covered by its high population density, the 'central belt' between Glasgow and Edinburgh, the roots of that dominance are to be analysed in terms of the particular capabilities necessary to achieve and sustain their hierarchical positions. The most obvious way to examine how such hierarchical relationships form and relate to each other is to consider how they exert themselves in what are still the principal criminal markets: those of Class A drug supply. Examining the process through this door enables exploration of the relationships between SOCGs, and how they interact with looser retail networks further down the chain. 


\section{The shape of supply lines - the 'class A' drugs market in Scotland}

Intelligence disseminations relating to the principal SOCGs involvement in Class A drugs markets indicate the following outline profile of the relevant supply chains:

The structure presented at the next page, appears consistent with the generic view of Scottish SOC taken in the Scottish Government paper (Scottish Government, 2017), in that the top end is characterised by hierarchical structures and the bottom end by looser network structures. Given the illegal nature of the activity, it is not a surprise this should be so. At the top end, importation requires access to significant resources, not least financial, to participate in the relevant transactions. At the bottom end, visible street level retail transactions require the deployment of expendable human assets where the linkages to controlling forces have to be obscured. A further feature of significance is that cash management is a separate process from drug distribution management, with the detail of cash collection mechanisms closely guarded.

Figure 1

Scheme of supply chains between organised crime groups

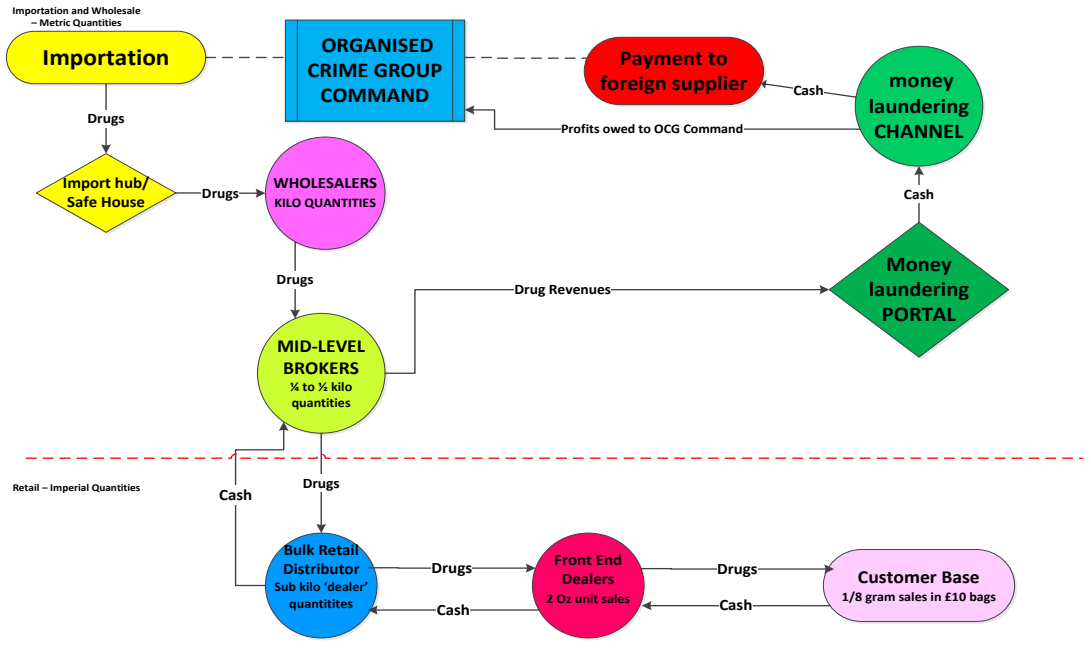


The key frontier is the level at which the controlling influences interface with the local distribution and retail networks. This is represented above by the red dotted line. There is a simple way to ascertain where an individual stands in relation to this frontier in Scotland: above this dotted line, the consignments are dealt in kilos or fractions of kilos; below this dotted line, the units are dealt in imperial measure: principally ounces or fractions thereof (although, confusingly, some retail bag amounts for sale at street level are measured in grams).

The size of the financial commitment involved at the top of the scale, at the importation level, can be gauged from the major drug seizure in the spring of 2016 in the North Sea by the NCA, working with Police Scotland, in Operation Screenplay (The Herald, 2016). A Turkish trawler, MV Hamsun, was intercepted in the North Sea off the east coast of Scotland. The NCA 'deep rummage' team were called in to examine and search the impounded vessel. After an extensive and very probing search, an extensive illicit cargo of cocaine was found: it amounted to a haul of 3,2 tonnes. Translated into street prices, the value of the haul was in excess of $£ 500$ million.

As Reuter (2004) has pointed out the use of street prices to value an intercepted cargo is not really justified, in that it doesn't reflect the true value of the commodity in the place and condition where it is found, the cost value relevant to these preferred parameters indicated a value of this drugs consignment of $£ 80$ million plus. MV Hamsun was transporting a multi-million pound investment of which a sizeable economic return would be expected: likely to be between $50 \%$ and $100 \%{ }^{3}$ (Gash, 2016). The return expected from this level of investment would have to be realised from a revenue stream (i.e. an actual cash stream) sourced from physically dirty cash revenues earned at the retail end of the chain, and which involved their subsequent collection, secretion, and distribution to investors. The processes required to achieve these functions, and thus realise the economic return from the multi-million pound investment, would also involve the deployment of specific service attributes at various levels of the structure to enable the revenue to be secured and realised.

3 Gash (2016) uses an estimate of 69\%, for example. 
The set of required arrangements to harvest the money is almost always quite separate from the various co-ordinating arrangements relevant to distribution of the actual commodity. Again, there is a critical interface to be discerned at the level of the red dotted line: the amounts collected from the distribution networks below the line represent the accumulated cash resource (e.g. the $£ 1,6$. million seized in Operation Escalade) that requires to be secreted into a company or a bank account through a professionally managed laundering process. In some cases this is achieved by physical transportation of the cash abroad; in others money is secreted in a network of legitimate businesses controlled by specialist financial controllers who serve a number of different SOCG clients.

Empirical studies of the constituent elements of the chain are often limited in their scope to those aspects of it that are visible i.e. the local warehousing and street retain elements. At these levels, a degree of physical contiguousness exists between the commodity and the revenue it generates that is not present elsewhere in the chain. If, however, the process arrangements relating to how the required financial return reaches the importers, and indeed the investors standing behind the importers, are not properly understood - that is, the parts of the process which are usually kept separate from the commodity - then the relevant structures may appear to be flatter than is actually the case. ${ }^{4}$

The missing elements of the picture derive to a large extent from the traditional law enforcement bias that favours commodity as the focus of attention, as opposed to the revenue it earns. Given that the players with the most power in the relevant governing structures will generally not go anywhere near the commodity, this implies that one of the prizes for seniority in this industry is protection, if not immunity, from prosecution. In addition, the players at this level must maintain the ability to enjoy access to criminal revenue streams.

The oft expressed need to do more about 'high end money laundering' (Financial Times, 2015) is a reflection of the extent to which this problem has proved elusive to traditionally equipped law enforcement agencies. This is at least partly due to a lack of understanding of what the relevant business processes are which secure that revenue. This may also be read as

4 See Gash (2016) for an example of this line of argument, which is based on Reuter (2004), and also conversations with him. 
a testament to the effectiveness of the design of these processes, or at least how jealously they are protected. It is an important gap, which counts against a proper understanding of the ways SOCGs relate to each other and the markets they participate being obtained.

A related but equally important challenge, however, is to find ways of properly visualising, or conceptualising, the attributes necessary to be able to exert the necessary control and influence in these realms. If these attributes can be properly identified, the prospect opens up of being able to identify and exploit, from a law enforcement point of view, structural weaknesses and vulnerabilities. Understanding the factors necessary for the formation of established hierarchies, therefore, provides an entry point for considering the factors which influence all capabilities relevant to participating in SOC, since hierarchies have to engage with network forms of association to profitably participate in these markets.

Understanding how those relationships work requires the formulation of a suitably based theoretical framework. The objective from a law enforcement point of view of developing such a framework would be to develop a practical template that would enable the relevant capabilities to be properly identified, so that they can be turned into vulnerabilities that can be targeted for law enforcement action.

\section{The formation of firms and the importance of transaction costs in both legal and illegal markets}

The first step to achieving this understanding is to analyse the dynamics that lie behind the relevant transactional relationships. The source of wealth and competitive success of any entity, including SOCGs, lies with its ability to successfully manage transactions. The entity, or 'firm', can essentially be defined in terms of the arrangements it engages in to achieve that.

In Ronald Coase's analysis (1937; see also Coase, 1960), firms are formed where functions and services cannot be accessed from the external market at a price which more than compensates for the increased transaction costs associated with dealing with an external supplier. The performing of these functions and services in-house become specialisations managed internally through hierarchical instructions. Different specialisations 
by different firms form the basis for the exchange of goods and services upon which a market economy is based. The Coase analysis relies heavily on the classic assumptions of efficient allocation of resources achieved through a properly functioning price mechanism, but the analysis still has contemporary relevance to the characteristics of the so called 'gig' economy, which has arisen in many instances as a consequence of the collapse of transaction costs across a number of service sectors. Firms are incentivised to outsource more and more functions as a result and reduce their own internal operations to core specialisations.

In the field of SOC, it is obvious that the natural discipline of the market will not reflect all of the relevant factors at play when determining whether or not to transact with another party. Illegal markets confer a number of different conditions: the threat of law enforcement; the extent to which a trading partner can be trusted in an unregulated environment; the threat of violence and so on. These are all factors likely to affect and distort the purely economic parameters relating to the relevant trading relationships. The theorising necessary to accommodate these features needs therefore to be able to accommodate the relevant non-market based features of transactions which can affect transactional outcomes.

Drawing on the Coase insights on firm formation, Oliver Williamson (1979) constructed a theory of economic activity based on a more detailed analysis of the costs and conditions relevant to economic transacting. This emphasised that economic organising could be essentially considered a problem of contracting, with the 'critical dimensions' of transacting being those of uncertainty, frequency, and a factor termed 'asset specificity.' This construct provides insights not only in respect of normal trading in legal markets between legal participants, but also SOCG trading in illegal markets too.

There are uncertainties about outcomes in both legal and illegal markets. Contracts cannot cover all contingencies, however well drawn. Other factors have to come into play in terms of the decision to transact with another party, the most obvious relating to the critical dimensions of 'uncertainty' and 'frequency'. For example, in terms of 'uncertainty', there are always natural boundaries of knowledge (or 'bounded rationality') which limit the number of possible counterparties that can be engaged with and the range of activities it is possible to engage in. Also, the dimension of 'frequency' in transacting is bound up in notions of trust. In situations 
where a new contracting party is identified, particularly in the highly cynical environment of SOC, certain questions arise, such as: am I going to be taken advantage of by this person - perhaps even in the same way that I, given the same opportunity, might very well take advantage of him? As with legal markets, the frequency and recurrence of transacting in illegal markets is contingent on the establishment of a suitable measure of trust between the transacting parties, and this tends to evolve and develop through repeated transacting. Transactions therefore occur in an environment of constant reputational evaluation and re-appraisal.

The Coase/Williamson analyses were both founded on the insight that firms and markets were alternative ways to organise transactions, with the decision as to which option was taken informed by evaluation of all the relevant transaction costs. The corollary of this is that firms tend to evolve in a way that encourages specialisms which are managed internally through hierarchical corporate structures and application of related cost and knowhow advantages exploited in the market place. The firm, as conceived by Williamson, is essentially characterised by these 'extra-market' specialisations; the ability to exploit and deploy advantage derived from being able to do certain things better than anyone else in that time and space. In the case of SOCGs, this state of affairs, where achieved, is partly because controllable conditions have been engineered to ensure this is the case, and will continue to be the case so long as the advantages conveyed by these specialisations prevail.

The establishment of these specialisms and their subsequent exploitation in the context of SOC have a particular relation to the formation of the third Williamson dimension, namely 'asset specificity,' which, in a paper entitled 'Hierarchy and Markets' (Williamson, 1973), he identified as the major indicator of hierarchy formation. It is the way in which SOC relates to this concept of 'asset specificity' that provides the key to understanding why SOC hierarchies form, and identifying the factors that enable them to form. 


\section{The significance of 'Asset Specificity' in explaining hierarchy formation}

'Asset specificity' can be defined as the extent to which investments made to support a particular transaction have a higher value to the firm than doing anything else. According to Klaus von Lampe, it means that, "certain resources such as specialised skills and machinery cannot be flexibly used for a variety of purposes." (Von Lampe, 2016: 149). This is asset specificity explained as if it is a limitation, as if it is a problem to be overcome. According to Von Lampe, organisations respond to this asset specificity problem in two ways: incorporation of specific skills into the organisation, and then backwards and forwards integration of sourcing or raw materials and distribution of finished product or service.

In SOC, however, asset specificity is not so much a challenge to be overcome as a condition to be engineered and then exploited. The principal reason for this is that the conditions of asset specificity enable the extraction of what are referred to as 'quasi-rents'. The successful organised crime boss looks to engineer conditions which enable control of a particular service capability, or control over a geographical area or key transit channel. The key characteristic of such an advantage is that use of the asset of capability is in demand from other users, thus conferring the ability to extract quasi-rents and sustain economic power and influence.

The two essential characteristics expressed in formal terms, as further elucidated by Per Bylund (2011), are high complementarity - the extent to which the relevant assets or commodities traded have utility value to a broad range of other firms; and low substitutability - the limited scope for other firms to access these assets or commodities from another source. Where these characteristics are present in respect of an asset, or a traded commodity, or a channel through which a commodity is traded, the achieved asset specificity conditions are transformed into what is referred to as a strategic asset.

The asset specificity conditions required to achieve such a strategic asset relate not only to the complementarity and substitutability variants indigenous to the transaction, but also the time and space in which the trade is conducted. Within these variables lie the reasons why certain players and groups in SOC exert a lasting influence, whereas others do not. Those able 
to engineer large scale shipments across borders and sea barriers, for example, are able to have an influence over the nature of the commodity supplied, and/or the price conditions, and/or the requirements relating to transportation and importation. All of these factors have the effect of increasing the value of the strategic asset of the relevant importation channel - consolidating the conditions of high asset specificity necessary for successful exploitation of it, to the exclusion of others who do not have access to it.

Control over strategic assets that allow dominance over distribution channels has been the key driver sustaining the influence of 'Ndrangheta in European drug markets and the Mexican cartels in North America. It is also of direct relevance to the Escalade SOCGs prominence in Scotland and the UK. In a different theatre of SOC, the same factors were identified by Campana (2015b) as explaining hierarchical influence in otherwise very disparate African human trafficking networks. Although the dominant modes of organisation were best characterised as loose networks, hierarchical influence could still be detected, derived from control of bottlenecks in the transportation process. These were the channels over which hierarchical authority could be imposed through the charging of quasirents.

\section{The interaction of hierarchy and networks}

As indicated, the trope of opposing hierarchies to networks does not help much in terms of understanding the Scottish SOC theatre: the evidence from SOCM indicates that hierarchical SOCGs are also active participants in network arrangements. The relevant theory relating to networks can, however, provide signposts as to what conditions are likely to be more suited to network forms of association.

Where the conditions amenable to the extraction of quasi rents do not exist, it follows that the influence of hierarchy in criminal markets is likely to be lessened. In these conditions, loose network type arrangements are more likely to be prominent, e.g., in the conduct of cross border low denomination drug transactions. The profile of the Class A drug supply chain in Scotland, characterised by the interaction of hierarchies and network, sets the challenge of devising analyses which will help explain how hierarchical SOCGs interact and manage these interactions - in particular those 
areas of activity where transacting participants do not enjoy strategic asset advantages, where the most common form of criminal business organisation are network formations.

Walter Powell identified networks as a means of satisfying the requirements of economic transaction making which was separate from the binary choice between top-down direction and discrete market exchange (Powell, 1990). His analysis considered the conditions under which networks were most likely to emerge - essentially fields in which knowledge and/or skills did not lend themselves to either monopoly control or expropriation by the wealthiest bidder. According to Powell, when partners were involved in ongoing complementary activities, the relationship between them was more likely to lend itself to mutually supportive information sharing. The basis of exchange was identified as essentially an exchange of distinctive competencies: "Networks of individuals engaged in reciprocal, preferential, mutually supportive actions. Networks can be complex: they involve neither the explicit criteria of the market, nor the familiar paternalism of the hierarchy" (Powell, 1990: 303). The exchange of distinctive competencies in terms of knowledge or skills was therefore considered more likely to occur in networks. By contrast, where competition occurred on the basis of price or manufacturing intensity, networks were less likely to be in evidence.

There is nothing, however, to prevent exchanges occurring simultaneously between entities relying on distinctive competencies for their competitiveness and other entities which rely on strategic assets to assert market dominance. The functioning of illegal markets actually requires such exchanges. The nature of Scottish drug supply chains requires a degree of co-operation between SOCGs of varying degrees of complexity and structure to enable the market to function.

This still leaves the question of how the various modes of organisation occurring within SOC gel together to provide coherent functioning markets. The answer lies in understanding the parameters relevant to the transactions that are necessary to make such markets and supply lines work; something that builds on the work of Coase and Williamson to accommodate all aspects of why one party transacts with another, and accommodates all types of structure that is relevant to the workings of SOC markets. 


\section{John Kay and the foundations of corporate success}

John Kay's analysis of the factors necessary for corporate success was founded on Williamson's work on transaction cost economics (Kay, 1993). According to Kay, contract structure, and therefore organisational form, adapts to the characteristics of the type of transactions to be handled. The value of any structure therefore lies in relational contracts, and this determines the mode of business organisation. The firm (including all varieties of SOCG) is defined by its contracts (or patterns of repeat transactional behaviour in SOCG environments) and relationships. Success, or 'added value' in a commercial context, is created by putting these contracts and relationships together. Differentiating factors between firms therefore lies in the quality and distinctiveness of its contracts, with their distinctiveness being at least as important as their quality. In most efficient markets, and probably all criminal markets, there are limited opportunities to make good contracts. The question at the heart of every firm's strategy, therefore, is 'why will we be better at doing this than anyone else?'

Success is obtained by developing a set of relationships which others are unable to make. The foundation to 'adding value' (which translates to being profitable and successful), is some kind of 'competitive advantage' - some feature of its relationships which other firms lack, and cannot readily produce. Powell's exchange of competencies alluded in his analysis of network arrangements is similarly founded on complementary distinctive capabilities. But Kay's analysis can extend to all types of transacting party, whether in the context of network structures or not. The only type of circumstance where this is not the case is where a firm relies solely, not on any such distinctive capability, but on its ability to exploit a strategic asset. This may be possible in the case of certain SOCGs, where it has engineered control over a supply route, a trading channel, or a key strategic technical asset. Even in these circumstances, however, the creation of the strategic asset is usually a function of a combination of competitive advantages being applied which have been founded on different distinctive capabilities. So what are these distinctive capabilities? Kay defines them as follows:

- Architecture - Architecture is the network of relational contracts within, or around, the firm. Firms might establish these relationships 
internally (through vertical integration), externally (with partners engaged in the same activities in other theatres), or among a group of firms engaged in related activities (networks based on complementarity);

- Reputation - Reputation is the most mechanism for conveying information to customers - or in SOCG terms, to partners and potential competitors (perhaps backed by a necessary degree of threat, or, alternatively, through financial muscle);

- Innovation - Innovation can deliver competitive advantage in itself, arising from being able to do something before anyone else can. Usually, however, according to Kay, it is more often associated with generating returns as a result of combining the innovation opportunity with other distinctive capabilities.

According to this analysis, the most powerful firms combine the leverage arising from all the distinctive capabilities they have access to and use them to re-inforce each other. This in turn can amount to the creation of the kind of strategic asset that enables collection of quasi-rents. The deployment of distinctive capabilities and/or strategic assets in relevant markets confers competitive advantage, and it follows that all successful SOCGs, however they are structured, and wherever they appear in criminal supply chains, fall to be analysed in these terms. This then offers a basis for constructing a means of identifying the key elements that enable SOCGs to function and be successful.

\section{Application of the Kay analysis to Escalade}

How can this theoretical foundation be applied in such a way as to provide workable insights relevant to SOC in practice? The Escalade example lends itself to analysis using the following matrix, which is based on the business model generation matrix of Osterwalder and Pigneur (2010). 


\section{Figure 2}

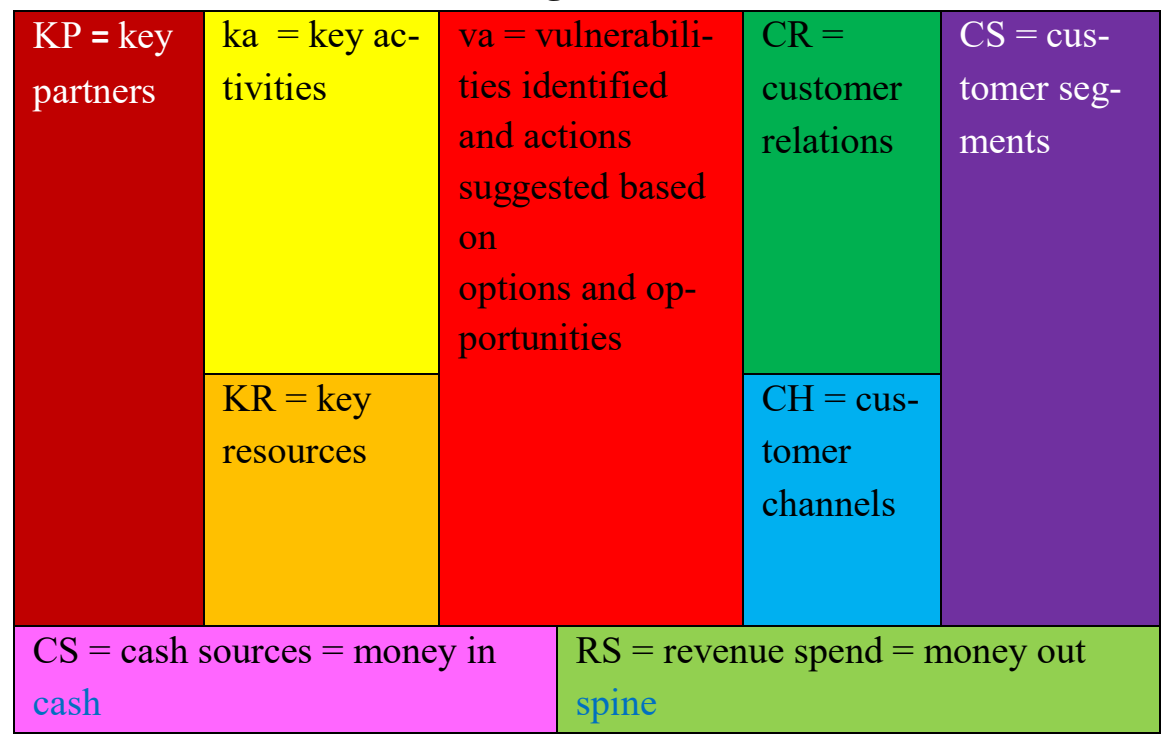

The relevant intelligence and/or information captured in relation to an SOCG can be classified according to the boxes of the matrix in order to determine its business profile. The left hand side relates to the Kay classifications of distinctive capabilities of architecture and innovation, and the right hand side relates to the distinctive capability of reputation as well as any strategic assets which can be exploited, such as control over drug distribution in a particular area or control of a key transit channel. In general terms, the $\mathrm{K}$ boxes taken collectively in this analysis relate to what an organisation does, and the ' $\mathrm{C}$ ' boxes taken collectively relate to the markets it serves. In the context of an SOCG, however, the ' $C$ ' boxes usually translate to what it controls, since the way in which SOCGs relate to the markets they serve is usually in terms of what they control.

Applying this analysis to Escalade, in particular in respect of identifying how it acquired a dominant position in Scottish SOC, the relevant explanatory factors can be broken down into the following distinctive capabilities:

- The key contact relationships that allowed the Escalade group to assert itself as a major importer were those it had been able to establish with main producers and cartels in South America and Mexico. This enabled it to have control over a greater portion of the supply stages, in particular those parts offering the highest rewards, i.e. the phases transporting 
the commodity across the Atlantic to Europe and West Africa, and then from continental Europe into the UK. The Escalade group did not, therefore, rely on supplies already imported to Europe from other parties. In financial terms, this enabled the group to earn gross profits of $£ 2$ million a week from Scottish drug markets alone, or £100 million a year. This revenue enabled the Escalade group to invest in further capabilities, which had the effect of consolidating and enhancing its competitive position as detailed below;

- The key resources used by the Escalade group included: the warehouse network referred to, comprising storage assets in both Scotland and Europe; transport logistics over land and sea; rigorous internal control processes; and also an exclusive access to encrypted phone technology, which it also supplied to other SOCGs on a commercial basis;

- In addition to the source contacts it had acquired in South America and Mexico, the key business partners were prominent Scottish SOCGs, themselves often hierarchical organisations with strong roots to specific territories, who served as its primary customer base;

- The key markets in the UK could therefore be accessed through the network of SOCG customers it had established. These provided the local distribution capabilities necessary to access and exert a dominant hierarchical influence over the cocaine and heroin trade in the West of Scotland and much of its central belt. The financial success of the Escalade SOCG also required a means of collecting the cash realised from retail sales and securing it. The way in which this was done became apparent in the course of the law enforcement action described below.

The above outline profile identifies the key distinctive capabilities of the Escalade SOCG. The methods used by law enforcement to tackle it essentially made use of these distinctive capabilities, by turning them into vulnerabilities. The approach can be summarised as follows:

- Concerted surveillance and telephony over a 12-month period led to the identification of the principal SOCG customers of Escalade, which it supplied by with large quantities of Class A drugs. During the course of this first phase of the enquiry, the network of covertly obtained industrial premises and vehicles was identified. It was established all premises occupied had been rented under aliases. All rental payments were made in cash and in advance, limiting contact with landlords in an 
attempt to leave no evidential trail. Similarly, all of the vehicles identified were registered and insured to false names and addresses. Group members were observed conducting anti-surveillance prior to attending at these locations for fear of compromise.

- A further protracted period of surveillance, and other enquiries revolving around the identified warehouses, was undertaken. This had the objective of identifying as many of the covertly obtained premises and vehicles as possible. During this period, the tradecraft and hierarchy of the SOCG was identified and search warrants were obtained for all of the covertly obtained premises.

- On a Police Scotland day of 'executive action', raids were made on all the warehouse premises. This resulted in discovery of: (i) the largest weapons cache ever discovered in Scotland; (ii) an extensive collection of state-of-the-art anti-surveillance equipment and encrypted phone technology; (iii) £1,6 million in cash stored in seismic spring units for ease of secretion in lorries and other vehicles.

- DNA evidence from the weapons identified nine senior members of the Escalade SOCG. This enabled them to be evidentially linked to the torture of the debtor who had failed to pay a $£ 30.000$ drug debt.

\section{The factors entrenching SOC hierarchical influence in Scotland's central belt}

If the principal strategic asset accounting for the Escalade dominance was its contact base and supply infrastructure, what accounts for hierarchical influence attributable to its principal SOCG customers? In some cases, it relates to established dominance over a distinct geographical area; with others it relates to its broad network of contacts that enable it access to high level drug transaction negotiations. In respect of each of these SOCGs, it is the practical measures they take to secure their revenues that most obviously defines their identity as a group, and the hierarchical relationships within that are a principal feature of that group.

One of the key benefits of these arrangements is the ability to access legitimate markets. Legitimate activities are sometimes undertaken for the legal profits to be obtained from them, but in many cases, they serve, either directly or indirectly, criminal objectives - money laundering in particular. 
It follows that assessment of SOCG business models must incorporate legitimate as well as illegitimate activities. The competitive position of a prominent SOCG is a function of how it manages and exploits interfaces between the two.

The most significant way in which Scottish SOCGs have done this has been to pool resources through centralised criminal money management facilities. Access to these facilities is itself a key distinctive capability which enables SOCGs to consolidate their position and accumulate wealth behind legitimate facades. The SOCGs with access to these facilities are those that feature in the top echelons of the SOCM rankings, which underline the impression that the top half of the profile of Class A drug supply in Scotland is indeed hierarchical. The extent of hierarchical influence extends down to the mid-level; aspiring SOCG players emerge from social drug networks to assume mid management roles. These roles require particular skill sets encompassing the ability to exercise discipline through threat and the management ability to secure the cash revenues that require to be secreted through money laundering portals (McLean et al., 2018). These individuals are prominent in SOCG intelligence disseminations, being the individuals most engaged at the front line, the open face of the hierarchical interests to whom they are answerable.

All of these SOCG groups, and indeed key enablers who flit between these groups, rely on established reputation to function. This often manifests as control exercised by a level of threat that is commonly perceived to be associated with that reputation; the distinctive capability which underpins how they are able to exert influence over the looser networks at the retail end of the supply chain. In essence, the expression of hierarchical influence is most obvious in the way in which relationships with looser, subordinate networks are conducted. In many senses Scottish SOC can be considered a network of these hierarchical influences, with the significant distinctive and differentiating capability common to each of them being the extent to which they are able to access and enjoy that influence in respect of these relationships.

The validity of this analysis is borne out by recent SOC developments in areas of Scotland which are beyond the usual areas of territorial control of the central belt based SOCGs (The Sunday Post, 2019). In contrast to the central belt, the northern cities of Aberdeen and Inverness do not have a tradition of dominant indigenous SOCGs. Accordingly, these markets 
have always been more open for infiltration by SOCGs from other areas, including England and foreign SOCGs. The strategic asset of local market dominance is not present, allowing these territories to become open to 'County Lines' drug gangs from England and beyond.

\section{Conclusion}

Understanding transactional dynamics is the key to understanding relationships within SOC, in particular hierarchical influence. It is by identifying such influence that law enforcement stands the best chance of maximising its effectiveness against SOCGs. This falls to be done by targeting not just the SOC players and groups with the most influence, but also the capabilities and strategic advantages that sustain their hierarchical position. In Scotland, the need to import illegal commodities across a sea border and persistent territorial influences have underpinned the continuing influence of hierarchical forces, which have successfully adapted to contemporary market forces and economic conditions. A key manifestation of that adaptation process is the extent to which hierarchical influence is maintained through network structures.

Given these characteristics, in order to be effective, law enforcement responses to the developing challenges of SOC in Scotland requires adoption of analytical tools that will enable understanding of SOC transactional capabilities. These capabilities are changing all the time: the networked hierarchies of SOC are particularly well suited in terms of their sets of competitive advantages to dominate and exploit many emerging dynamic criminal markets. If unchecked, they will confer increasing governance power and SOC influence over legitimate as well as illegitimate markets, which is a developing feature of SOC hierarchical influence in Scotland. Access to professional assistance at a level capable of sustaining credible presence and influence in legitimate markets, not always in sectors with which SOC has been traditionally associated, provides a further raft of distinctive capabilities which serve to confer and sustain hierarchical influence.

Failure to control the corruptive capability of such influence - which is a function of increasing accumulations of criminal profits being deployed in legitimate markets - is likely to result in increasing SOC governance 230 
across a broader range of legitimate markets and activities. The nature of the risk to developed economies is that hierarchical influences within SOC will accordingly be protected behind a screen of legitimate companies whose success in legitimate markets is underwritten by criminal revenue streams. This is the modern theatre of SOC influence and activity in Scotland, and presents law enforcement with its most potent challenge.

\section{References}

Bylund, P., The Coasean and Williamson transaction cost theories of organisation: a critical analysis from a specialisation perspective. University of Missouri, 2011, available at

http://ageconsearch.umn.edu/bitstream/103616/2/Poster\%20submit\%20Bylund.pdf

Campana, P., The structure of human trafficking: lifting the bonnet on a Nigerian transnational network. British Journal of Criminology, 2016a, 56(1), 68-86.

Campana, P., Explaining criminal networks: strategies and potential pitfalls. Methodological Innovations, 2016b, 9(1), 1-10.

Coase, R.H., The nature of the firm. Economica, 1937, 4(16), 386-405.

Coase, R.H., The problem of social cost. Journal of Law and Economics, 1960, 3, 1-44.

Daily Record, 11 December 2017a, available at https://www.dailyrecord.co.uk/news/crime/torture-gang-broke-victims-leg-11677300.

Daily Record, 17 December 2017b, available at: https://www.dailyrecord.co.uk/news/crime/cocaine-gangster-faced-rap-over11707538.

Finckenauer, J.O., Problems of definition: what is organized crime?, Trends in Organized Crime, 2005, 8(3), 63-82.

Financial Times, Alarm bells ring as 'dirty cash' floods UK property market, Cynthia O'Murchu, 16 September 2015.

The Herald, Police still hunting for ringleaders of international cocaine smuggling operation. 11 July 2016. 
Gash, T., Criminal - the truth about why people do bad things. London: Allen Lane, 2016.

Hobbs, D., Lush Life - Constructing organised crime in the UK. Clarendon Studies in Criminology, Oxford: Oxford University Press, 2013.

Kay, J., Foundations of corporate success. Oxford: Oxford University Press, 1993.

McLean, R., J.A. Densley and R. Deuchar, Situating gangs within Scotland's illegal drugs markets. Trends in Organised Crime, 2018, 21(2), 147-171.

Morselli, C., Structuring Mr Nice: entrepreneurial opportunities and brokerage positioning in the cannabis trade. manuscript (http://citeseerx.ist.psu.edu/viewdoc/download?doi=10.1.1.464.3579), 1999.

Morselli, C., Assessing vulnerable and strategic positions in a criminal network. Journal of Contemporary Criminal Justice, 2010, 26(4), 382392.

Osterwalder, A. and Y. Pigneur, Business model generation. Hoboken, NJ: John Wiley \& Sons, 2010.

Powell, W.W., Neither market nor hierarchy - network forms of organisation. Research in Organisational Behaviour, 1990, 12, 295-336.

Reuter, P., The organisation of illegal markets: an economic analysis. Honolulu, HI: University Press of Pacific, 2004.

Scottish Government, Serious Organised Crime (SOC) in Scotland: A Summary of the Evidence. Edinburgh: Scottish Government, 2017.

Sunday Mail, 10 February 2019, available at www.dailyrecord.co.uk/news/scottish-news/scotlands-narcos/

Sunday Post, 10 February 2019, available at www.sundaypost.com/fp/threats-violence-and-death-as-county-linesdrugs-gangs-seize-homes-in-towns-and-villages-across-rural-scotland/ von Lampe, K., Organized Crime: Analyzing illegal activities, criminal structures, and extra-legal governance. Thousand Oaks, CA: Sage, 2016a.

von Lampe, K., The ties that bind: a taxonomy of associational criminal structures. In G.A. Antonopoulos (ed.), Illegal Entrepreneurship, Organised Crime and Social Control. Cham: Springer, 2016b.

Williamson, O.E., Transaction-cost economics: the governance of contractual relations. Journal of Law and Economics, 1979, 22(2), 233-261. 
Williamson, O.E., Transaction cost economics. In R. Schmalensee and R.D. Willig (eds.), Handbook of industrial organisation (Volume 1, pp 135-182), Amsterdam: North-Holland, 1989.

Williamson, O.E., Markets and hierarchies: some elementary considerations, American Economic Review, 1973, 63(2), 316-325. 